\title{
Structural analysis using three-component acceleration time histories caused by shallow crustal fault earthquakes with a maximum magnitude of $7 \mathrm{Mw}$
}

\author{
Windu Partono ${ }^{1, *}$, Yulita Arni Priastiwi ${ }^{1}$, Nuroji $^{1}$, Indrastono Dwi Atmanto ${ }^{1}$, Bambang Pardoyo ${ }^{1}$, Trinita Octaviani \\ Gultom $^{1}$ and Yanuar Tampubolon ${ }^{1}$
}

${ }^{1}$ Civil Engineering Department, Diponegoro University, 50275 Semarang, Indonesia

\begin{abstract}
Research on the improvement of Indonesian seismic hazard maps has already been carried out by the National Center for Earthquake Studies in 2017. One important global data obtained from this research related with all earthquake sources mechanism which might be used for building design and evaluation. Based on this research there are two important and closest earthquake sources to Semarang, Lasem fault (strike slip mechanism) and Semarang fault (reverse mechanism). This paper presents the dynamic structural evaluations of the hospital building (approximately 49 meters height) located in Semarang, Indonesia, by conducting two seismic load functions, two-component surface spectral acceleration (X and Y directions) developed from Indonesian Seismic Code SNI:1726-2012 and threecomponent (North-South, East-West and Vertical) of surface acceleration time histories. All acceleration time histories were modified from three earthquake events which represents Semarang fault earthquake scenarios and developed from earthquake events with magnitude from 6.3 to $6.9 \mathrm{Mw}$ and the maximum distance of building to earthquake epicentre $15 \mathrm{Km}$. Based on the floor deformation and the drift ratio results calculated using dynamic analysis, the building is predicted has the capability on resisting earthquake scenarios up to a maximum magnitude $7 \mathrm{Mw}$ with minimum epicentre distance $10 \mathrm{Km}$.
\end{abstract}

\section{Introduction}

The dynamic stability analysis of high rise building in Indonesia usually performs by conducting two different earthquake model functions, surface response spectral acceleration (SRSA) and surface acceleration time histories (SATH) functions. The first function model can be developed from Indonesian Seismic Code SNI 1726:2012 [1]. However the second function usually developed from seismic records collecting from earthquake event using seismometer equipments. The stability evaluation of a building against earthquake forces is difficult to be predicted by implementing SRSA. The capability of a structure in resisting earthquake forces can be predicted by conducting SATH functions. This paper describes the dynamic structural analysis for predicting stability performance of an existing hospital building located in Semarang, by conducting two different seismic forces, two-directions $[\mathrm{X}(100 \% \mathrm{X}+30 \% \mathrm{Y})$ and $\mathrm{Y}(30 \% \mathrm{X}+100 \% \mathrm{Y})]$ of SRSA and three-component [North-South (N/S), East-West $(\mathrm{E} / \mathrm{W})$ and Vertical $(\mathrm{V})]$ of SATH. The object of study is a reinforced concrete structure $\left(78.6 \times 22 \mathrm{~m}^{2}\right.$ and 48.73 meters height) and located at SE (soft soil) site class [1].

To perform the structural analysis SRSA data was developed using [1] and three-component SATH data were developed by conducting response spectral matching analysis (RSMA) and site specific analysis (SSA) at the building location. Three-component SATH were developed from three different earthquake events with magnitude (M) from 6.3 to $6.9 \mathrm{Mw}$ and the maximum distance of the building to the earthquake epicentre (R) is 15 Kilometres. Each earthquake event has original or initial three-component acceleration time histories (ATH). All ATH were collected from three earthquake events outside Indonesia representing Semarang fault (reverse mechanism) earthquake source. Simulated earthquake scenarios analyses were carried out in this study due to incomplete and the difficulties of getting data related with Semarang fault earthquake.

The structural analysis was carried out by conducting 3-D structure model and applying live loads, dead loads and two seismic load functions model (SRSA and SATH) and following the same criteria proposed by $[1,2$ and 3]. The purpose of the analysis is to obtain the floor deformation and the drift ratio due to all building loads model. The floor deformation and the drift ratio calculation results from both seismic function models were then compared to get the information of building capability against specific earthquake scenario.

The SATH used in this study for structural analysis were developed using RSMA and SSA. The objective of RSMA is to obtain modified ATH which shall be matched with Semarang fault earthquake scenario.

* Corresponding author: windu bapake_dila@yahoo.com 
RSMA was performed until 4 seconds spectral period using two different horizontal spectral acceleration targets (N/S and E/W directions) and one vertical spectral acceleration target ( $\mathrm{V}$ direction). The horizontal spectral acceleration targets were developed using three attenuation functions proposed by [4, 5 and 6]. However another three attenuation functions proposed by [7, 8 and 9] were conducted for developing vertical spectral acceleration target. All modified ATH calculated from RSMA were then propagated from bedrock elevation to the surface elevation by conducting SSA to obtain SATH. SSA was carried out following the same methods proposed by [10 and 11) and using NERA software [12].

\section{Research details}

\subsection{Geotechnical and geological investigations}

Two, 40 meters depth, boring investigations were carried out at the building site for designing substructure and obtaining the site soil class. Based on the $\mathrm{V}_{\mathrm{s} 30}$ value (average value of shear wave velocities at top 30 meter soil layers) the building is located at SE (soft soil) site class. The value of shear wave velocity for every soil layer up to $30 \mathrm{~m}$ depth was calculated using [13, 14 and 15]. Fig. 1 shows the site soil class map of Semarang and the building location. The site soil class map was developed based on 190 boring measurements for the whole area of the city [16]. As can be seen in this figure site soil class (SE) is distributed on the northern part, SD (medium soil) and SC (hard soil) site classes are distributed on the middle and southern part of the city.

Two single station feedback seismometer (SSFC) investigations were also carried out for predicting bedrock elevation. Bedrock elevation prediction is important for SSA. The bedrock (rock having a minimum of shear wave velocity of $760 \mathrm{~m} / \mathrm{s}$ ) elevation was predicted by conducting Horizontal to Vertical Spectral Ratio (HVSR) analysis proposed by [17]. Based on the SSFC investigations and HVSR analysis the depth of bedrock elevation at the building location is estimated at 96-100 meter below the surface layer.

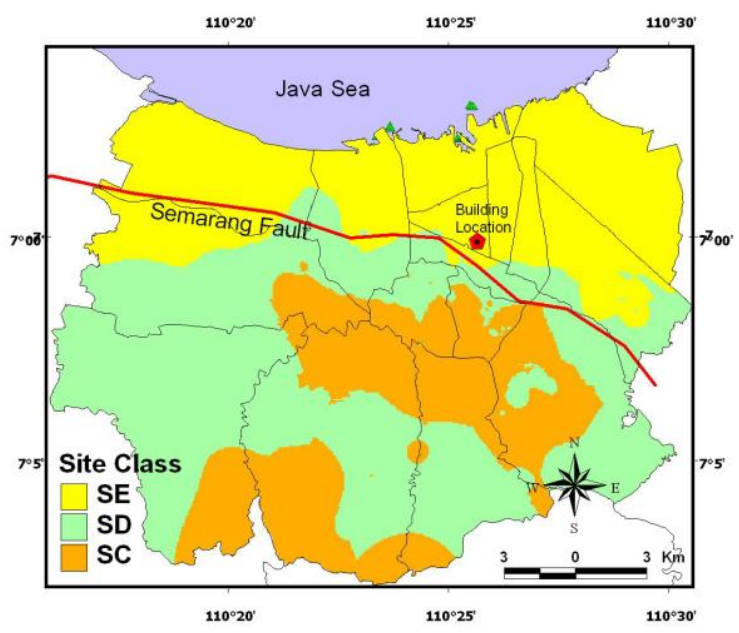

Fig. 1. Building location and site class map of Semarang.

\subsection{Development of acceleration time histories}

All original three-component ATH used in this study were collected from database prepared by Pacific Earthquake Engineering Research (PEER). The ATH were collected from three different earthquake events, Chi-Chi Taiwan earthquake 1999 (magnitude 6.3 Mw), San Simeon California USA earthquake 2003 (magnitude $6.52 \mathrm{Mw}$ ) and Iwate Japan earthquake 2008 (magnitude $6.9 \mathrm{Mw}$ ). The original ATH were collected from earthquakes having reverse fault mechanism which represents Semarang fault earthquake mechanism. Table 1 shows the information of epicentre distance for all earthquake events. Epicentre distance selection conducted in this study, as can be seen in this table, depends on the position of the building against Semarang fault trace. The closest distance of the building to Semarang fault trace is less than $2 \mathrm{Km}$. Due to the difficulties of data related with the actual distance and the requirement for structural analysis all ATH were collected base on Table 1 .

Table 1. Earthquake epicentre distances data.

\begin{tabular}{|c|c|}
\hline Earthquake Sources & Epicentre Distance (Km) \\
\hline Chi-Chi, Taiwan & 5.72 and 8.34 \\
\hline San Simeon, USA & 5.07 and 6.97 \\
\hline Iwate, Japan & 7.82 and 11.68 \\
\hline
\end{tabular}

All ATH collected from all earthquake events shall be matched with earthquake scenarios that could be produced by Semarang fault earthquake. RSMA was carried to obtain modified ATH using spectral targets which is developed based on the magnitude and epicentre distance. Fig. 2 shows all horizontal spectral targets developed using [4 - 6] and Fig. 3 shows all vertical spectral targets developed using [7 - 9].

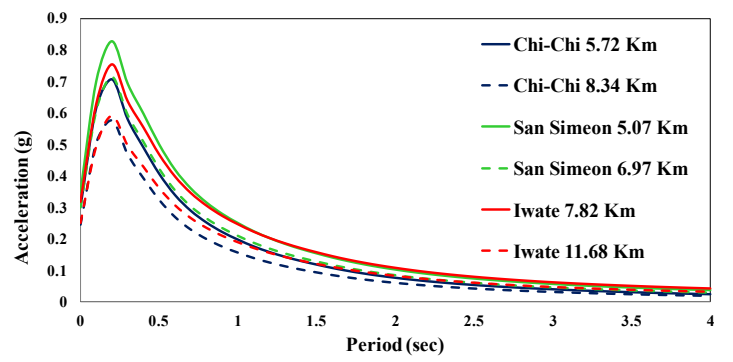

Fig. 2. Spectral acceleration targets for horizontal (N/S and $\mathrm{E} / \mathrm{W})$ components.

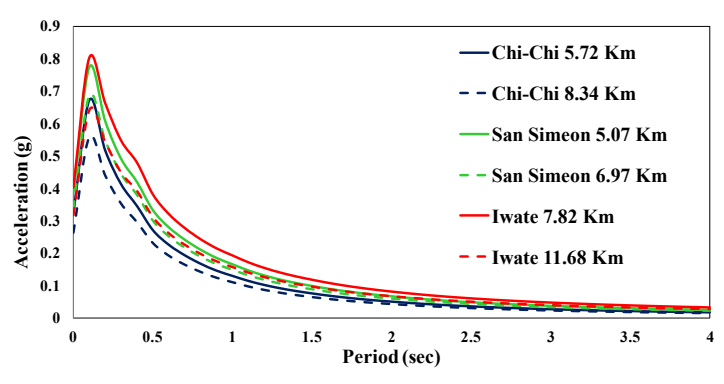

Fig. 3. Spectral acceleration targets for vertical (V) direction. 
RSMA conducted in this study was carried out using the same method proposed by [18]. The purpose of this analysis is to get the modified ATH which shall be matched with ATH that could be produced by Semarang fault earthquake. Initial and matched ATH should have similar shape. Fig. 4 shows three initial ATH which represents three-component time histories $(\mathrm{N} / \mathrm{S}, \mathrm{E} / \mathrm{W}$ and $\mathrm{V})$ collected from San Simeon earthquake $(\mathrm{M}=6.52 \mathrm{Mw}$ and $\mathrm{R}=6.97 \mathrm{Km}$ ). Fig. 5 shows three matched ATH of San Simeon earthquake ( $M=6.52 \mathrm{Mw}$ and $\mathrm{R}=6.97 \mathrm{Km})$ calculated using RSMA.

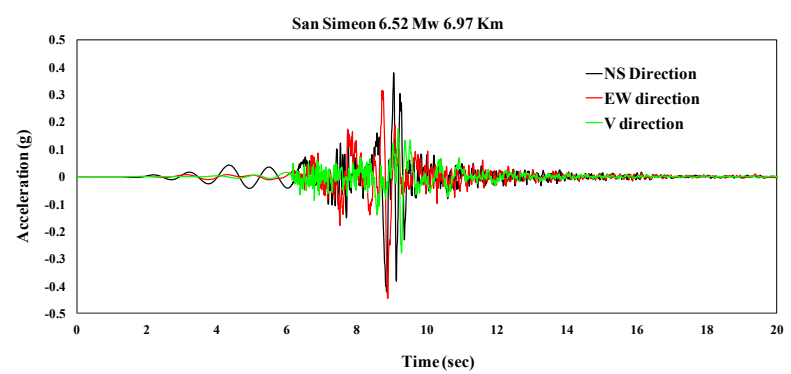

Fig. 4. Initial ATH of San Simeon earthquake $M=6.52 \mathrm{MW}$ and $\mathrm{R}=6.97 \mathrm{Km}$.

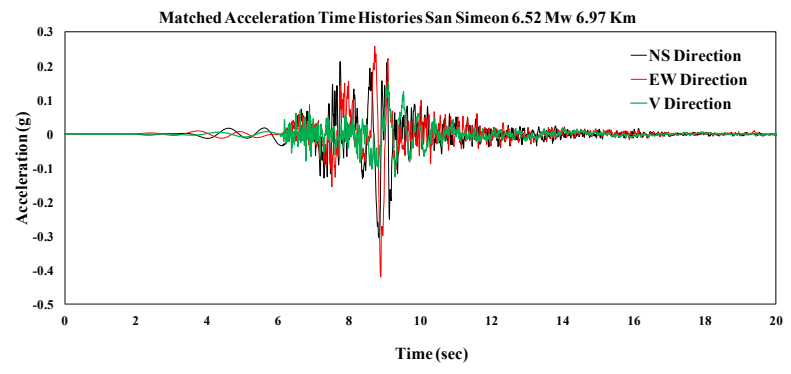

Fig. 5. Matched ATH of San Simeon earthquake M=6.52 MW and $\mathrm{R}=6.97 \mathrm{Km}$.

\subsection{Site specific analysis (SSA)}

The objective of SSA is to obtain the SATH by conducting propagation analysis of the matched ATH from the bedrock elevation to the surface elevation. The data needed for SSA are bedrock elevation and soil profile data (unit weight and shear wave velocity) from the bedrock elevation through the surface elevation and the ground water level at building position. Fig. 6 shows the unit weight and the shear wave velocity profiles at the building location calculated based on the average data from two boring investigations. Due to the difficulties of soil data below 40 meter soil elevation through the bedrock elevation, all unit weight of the soil data below 40 meter soil elevation were assumed to be equal with the unit weight of the soil layer at 40 meter soil elevation or the final depth of boring investigation. However the shear wave velocity data below 40 meter soil elevation was linearly interpolated until bedrock elevation (Vs at bedrock elevation is $760 \mathrm{~m} / \mathrm{s}$ ). The bedrock elevation was predicted based on two SSFC investigation locations and calculated using HVSR analysis proposed by [17]. Based on HVSR analysis the predicted bedrock elevation at the building locations is $96-100 \mathrm{~m}$ below the surface soil layer. Fig. 7 shows three-component SATH of San Simeon earthquake scenario $(\mathrm{M}=6.52 \mathrm{Mw}$ and $\mathrm{R}=6.97 \mathrm{Km})$ developed using SSA. As it can be seen on this figure the peak SATH at bedrock elevation is slightly smaller than the peak ATH at bedrock elevation.
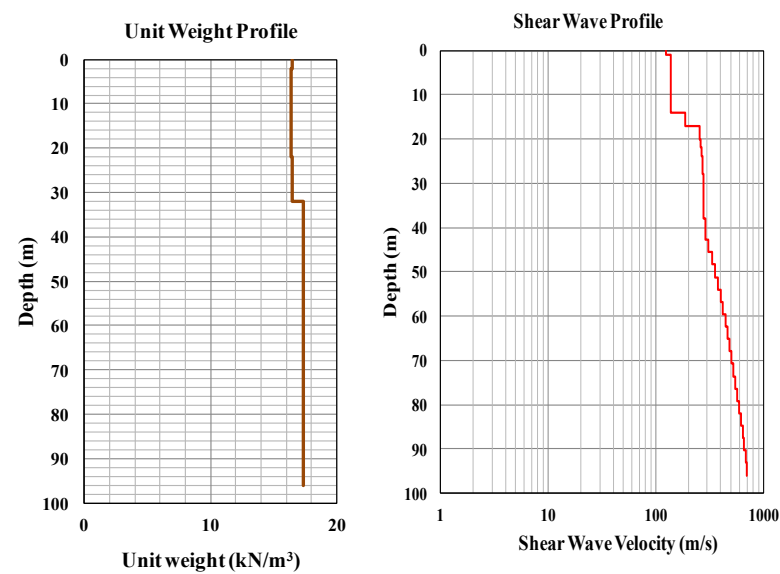

Fig. 6. Unit weight and shear wave velocity profiles at building location.

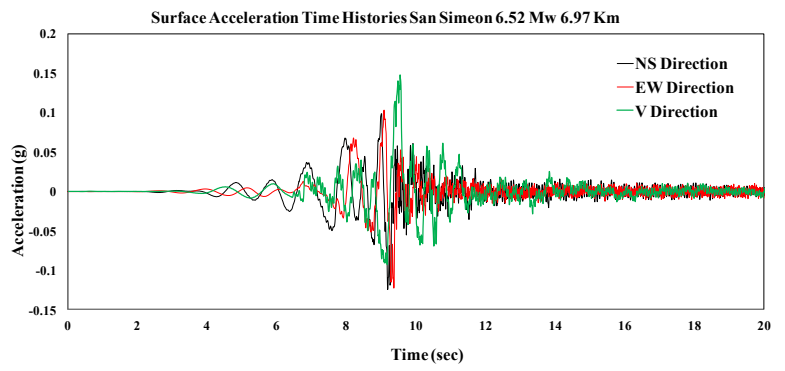

Fig. 7. SATH of San Simeon earthquake $\mathrm{M}=6.52 \mathrm{MW}$ and $\mathrm{R}=6.97 \mathrm{Km}$.

\subsection{Structural analysis}

The structural analysis was carried out by conducting two seismic load function models, SRSA and SATH. The purpose of this analysis is to get the information of building stability (floor deformation and internal drift ratio). The building stability results calculated using SRSA and SATH were then compared for predicting the building resistance capability against a specific earthquake event which represents Semarang earthquake scenario. If the floor deformation or the drift ratio calculated using SRSA greater than the same values calculated using SATH from a specific earthquake scenario, the building is predicted has a capability to resist the seismic forces which represents Semarang fault earthquake scenario. However if the floor deformation or the drift ratio calculated using SRSA less than SATH, the structure is predicted not strong enough to resist the seismic forces which could be produced by Semarang fault earthquake. Fig. 8 shows the 2-D structure model which represents the actual building evaluated in this study.

Based on two dynamic model analyses the floor deformation and the drift ratio profile of the building can be evaluated. Fig. 9 shows the floor deformation of the building caused by two-component SRSA (Y and X) and three-component SATH caused by Chi-Chi Taiwan earthquake $(\mathrm{M}=6.3 \mathrm{Mw}$ and $\mathrm{R}=8.34 \mathrm{Km})$. Fig. 10 shows the drift ratio of the building caused by the same SRSA ( $\mathrm{Y}$ and $\mathrm{X}$ ) and SATH caused by Chi-Chi Taiwan 
earthquake $(\mathrm{M}=6.3 \mathrm{Mw}$ and $\mathrm{R}=8.34 \mathrm{Km})$. Based on those two figures it can be predicted that in terms of the deformation and the drift ratio values, the building is strong enough on resisting an earthquake forces due to Semarang fault earthquake scenario $(\mathrm{M}=6.3 \mathrm{Mw}$ and $\mathrm{R}=8.34 \mathrm{Km})$.

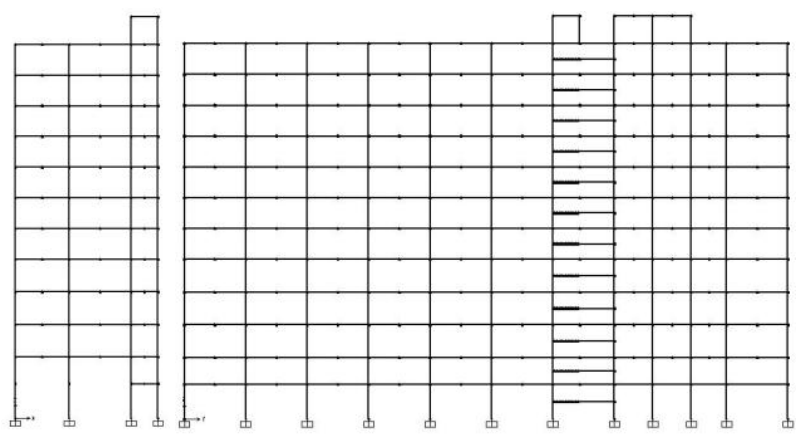

Fig. 8. 2-D Structure model.

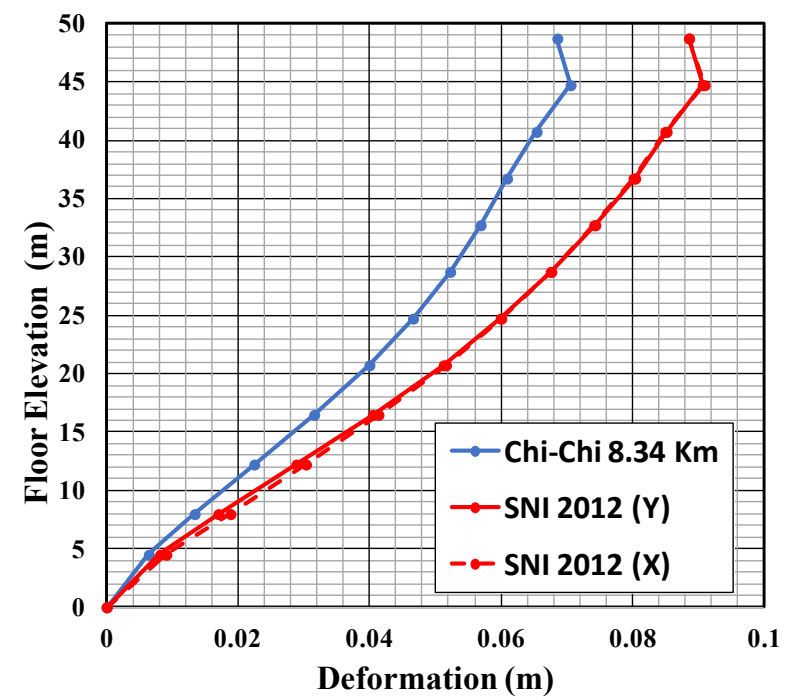

Fig. 9. Floor deformation due to Chi-Chi Taiwan earthquake $(\mathrm{R}=8.34 \mathrm{Km})$ and SRSA ( $\mathrm{Y}$ and $\mathrm{X})$.

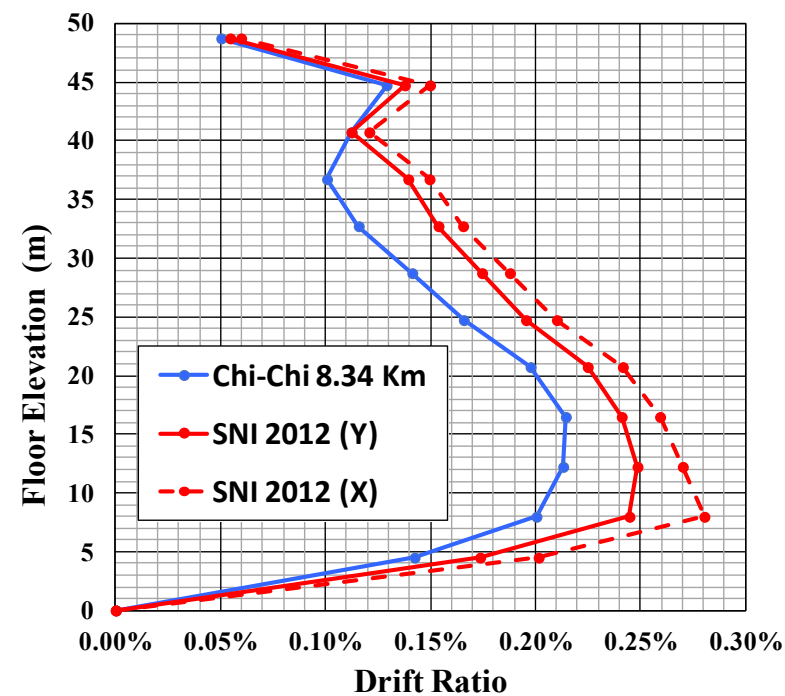

Fig. 10. Drift ratio due to Chi-Chi Taiwan earthquake $(\mathrm{R}=8.34$ $\mathrm{Km})$ and SRSA (Y and $\mathrm{X})$.

\section{Results and discussion}

The floor deformations and the drift ratio of the hospital building were calculated using three-component SATH causes by Chi-Chi Taiwan, San Simeon USA and Iwate Japan earthquake scenarios. All three-component SATH represents Semarang fault earthquake scenarios. The floor deformations and the drift ratio were also calculated by conducting SRSA developed from [1]. Fig. 11 shows the floor deformation calculated using SRSA ( $\mathrm{Y}$ and $\mathrm{X}$ ) and three-component SATH from three different earthquake events (having an epicentre distance of $5-10 \mathrm{Km})$. Fig. 12 shows the drift ratio of the building causes by SRSA ( $\mathrm{Y}$ and $\mathrm{X}$ ) and threecomponent SATH from three different earthquake events (having an epicentre distance of 5-10 Km). As can be seen in these two figures, based on the floor deformation and the drift ratio calculation results, the building is predicted strong enough to resists seismic forces caused by Semarang fault earthquake (M maximum $6.52 \mathrm{Mw}$ and $\mathrm{R}$ from 5 to $10 \mathrm{Km}$ ). However the building is predicted not strong enough to resists seismic forces caused by Semarang fault earthquake scenario $(\mathrm{R}=6.9$ Mw and $\mathrm{R}$ less than $10 \mathrm{Km}$ ).

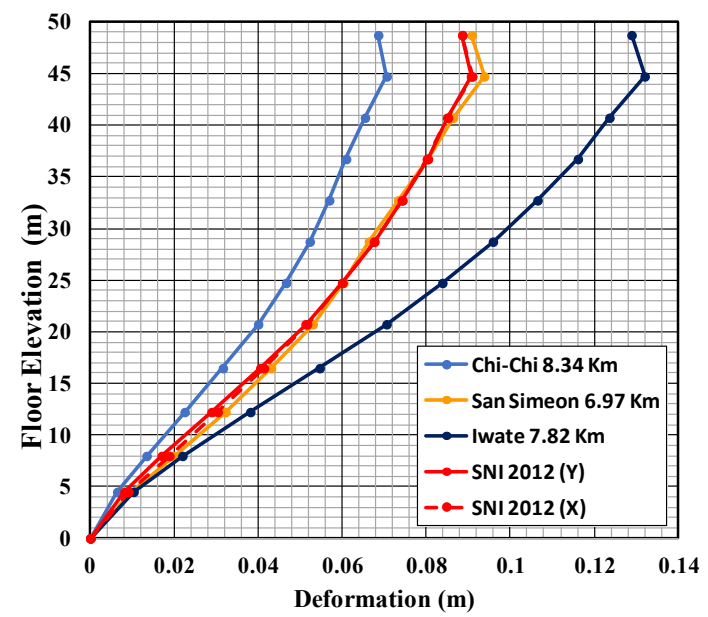

Fig. 11. Floor deformation due to SRSA ( $\mathrm{Y}$ and $\mathrm{X}$ ) and three earthquake forces $(\mathrm{R}=5$ to $10 \mathrm{Km})$.

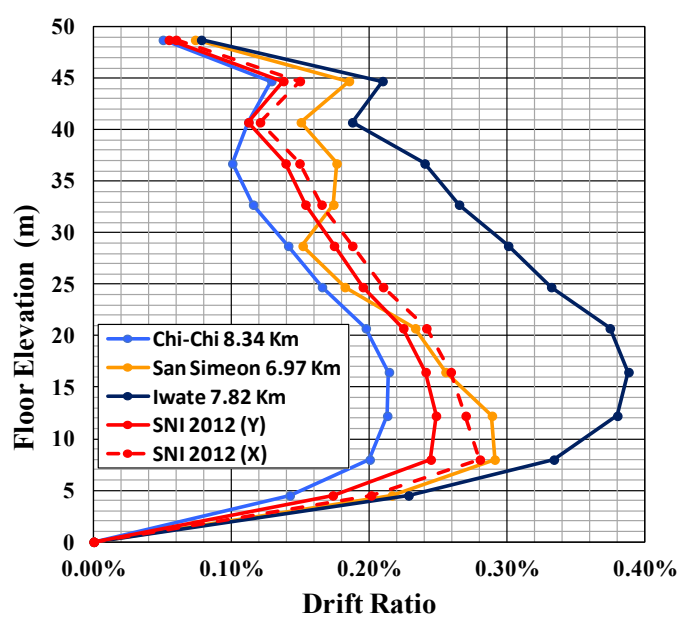

Fig. 12. Drift ratio due SRSA ( $\mathrm{Y}$ and $\mathrm{X}$ ) and three earthquake forces $(\mathrm{R}=5$ to $10 \mathrm{Km})$. 
As can be seen in Fig. 11 and Fig. 12 based on the deformation and the drift ratio results, the building is predicted not strong enough to resists a seismic force due to the Iwate earthquake $(\mathrm{M}=6.9 \mathrm{Mw}$ and $\mathrm{R}=7.82 \mathrm{Km})$. To evaluate the capability of the building against Iwate earthquake scenario, increasing of epicentre distance scenario was carried out by conducting Iwate earthquake $(\mathrm{R}=11.68 \mathrm{Km})$. The deformation and the drift ratio caused by this earthquake scenario were then evaluated. Fig. 13 and Fig. 14 show the difference between two scenarios of Iwate earthquake $(\mathrm{M}=6.9 \mathrm{Mw}$ and two difference $\mathrm{R}=7.82 \mathrm{Km}$ and $\mathrm{R}=11.68 \mathrm{Km}$ ). As can be seen in Fig. 13 and Fig. 14, the building is predicted strong enough to resist a seismic force produced by Iwate earthquake $(\mathrm{M}=6.9 \mathrm{Mw}$ and $\mathrm{R}$ greater than 11.68 $\mathrm{Km})$.

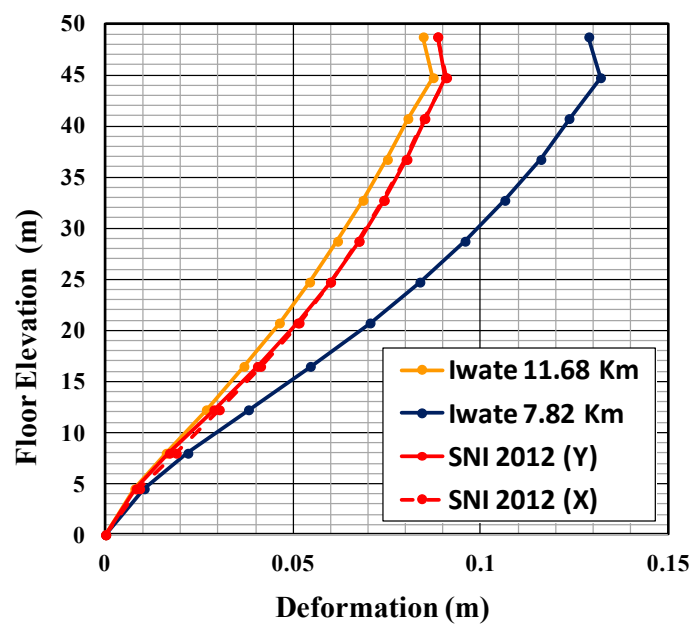

Fig. 13. Deformation due to SRSA ( $Y$ and $X$ ) and Iwate earthquake with $\mathrm{R}=7.82 \mathrm{Km}$ and $\mathrm{R}=11.68 \mathrm{Km}$.

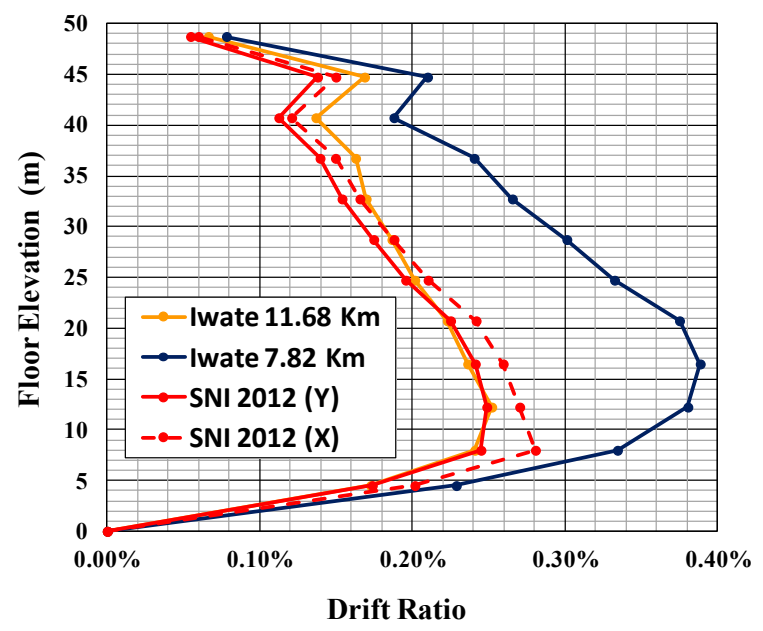

Fig. 14. Drift ratio due to SRSA ( $Y$ and $X$ ) and Iwate earthquake with $\mathrm{R}=7.82 \mathrm{Km}$ and $\mathrm{R}=11.68 \mathrm{Km}$.

Comparative study for evaluating the stability of the structure caused by (one-component, two-component and three-component) of Iwate earthquake $(\mathrm{M}=6.9 \mathrm{Mw}$ and $\mathrm{R}=7.82 \mathrm{Km}$ ) was also carried out in this study. Based on this comparative study, it seems that the deformation of the structure caused by one-component $\mathrm{SATH}$ is smaller than the deformation calculated using
SRSA ( $\mathrm{Y}$ and $\mathrm{X}$ ). The ratio of the floor deformation caused by one-component SATH of Iwate earthquake to SRSA ( $\mathrm{Y}$ and $\mathrm{X}$ ) is $57.60 \%$ up to $73.38 \%$. However the ratio of the floor deformation caused by two component SATH to SRSA ( $\mathrm{Y}$ and $\mathrm{X}$ ) is $113.46 \%$ up to $145.52 \%$. The deformation caused by two-component SATH is equal with the deformation caused by three-component SATH. Table 2 shows the ratio of floor deformation caused by one-component, two-component and threecomponent SATH of the Iwate earthquake $(\mathrm{M}=6.9 \mathrm{Mw}$ and $\mathrm{R}=7.82 \mathrm{Km}$ ) and the deformation caused by SRSA ( $\mathrm{Y}$ and $\mathrm{X}$ ).

Fig. 15 shows the floor deformation of the structure caused by one-component, two-component and threecomponent SATH of Iwate earthquake $(\mathrm{M}=6.9 \mathrm{Mw}$ and $\mathrm{R}=7.82 \mathrm{Km}$ ) and SRSA ( $\mathrm{Y}$ and $\mathrm{X}$ ). Fig. 16 shows the drift ratio of the structure caused by one-component, two-component and three-component SATH of Iwate earthquake $(\mathrm{M}=6.9 \mathrm{Mw}$ and $\mathrm{R}=7.82 \mathrm{Km})$ and SRSA ( $\mathrm{Y}$ and $\mathrm{X}$ ). As can be seen in Fig. 15 and Fig. 16 the deformation and the drift ratio curves of the building caused by two-component and three-component SATH are equal or coincided each other.

Based on Fig. 15, Fig. 16 and Table 2 it can be seen that the vertical component of SATH has no impact to the stability analysis results of the structure. The performance of the building stability caused by vertical component of SATH depends on the foundation used in the structure. The building evaluated in this study is located at SE site class and constructed using deep pile foundation to support the upper structure. All joint reaction model use for dynamic structural analysis is fix joint which represents deep pile foundation. Based on this condition it is important to justify whether or not the vertical component of SATH used for structural analysis.

Table 2. The ratio of floor deformation caused by SATH Iwate earthquake $(\mathrm{M}=6.9 \mathrm{Mw}$ and $\mathrm{R}=7.82 \mathrm{Km})$ and SRSA (Y and $\mathrm{X}$ ).

\begin{tabular}{|c|c|c|c|}
\hline \multirow{2}{*}{$\begin{array}{c}\text { Floor } \\
\text { Elevation } \\
(\mathbf{m})\end{array}$} & \multicolumn{3}{|c|}{$\begin{array}{c}\text { Floor deformation ratio of SATH } \\
\text { (caused by Iwate earthquake) and } \\
\text { SRSA (Y and X) }\end{array}$} \\
\cline { 2 - 4 } & 1 -comp. & 2 -comp. & 3 -comp. \\
\hline 48.73 & $73.38 \%$ & $145.52 \%$ & $145.52 \%$ \\
\hline 44.73 & $73.48 \%$ & $145.13 \%$ & $145.13 \%$ \\
\hline 40.73 & $72.87 \%$ & $145.49 \%$ & $145.49 \%$ \\
\hline 36.73 & $72.01 \%$ & $144.89 \%$ & $144.89 \%$ \\
\hline 32.73 & $71.68 \%$ & $143.61 \%$ & $143.61 \%$ \\
\hline 28.73 & $70.74 \%$ & $141.96 \%$ & $141.96 \%$ \\
\hline 24.73 & $68.93 \%$ & $139.67 \%$ & $139.67 \%$ \\
\hline 20.73 & $67.14 \%$ & $136.67 \%$ & $136.67 \%$ \\
\hline 16.48 & $65.41 \%$ & $132.07 \%$ & $132.07 \%$ \\
\hline 12.23 & $62.79 \%$ & $125.64 \%$ & $125.64 \%$ \\
\hline 7.98 & $58.33 \%$ & $116.41 \%$ & $116.41 \%$ \\
\hline 4.5 & $57.60 \%$ & $113.46 \%$ & $113.46 \%$ \\
\hline 0 & 0 & 0 & 0 \\
\hline & & & \\
\hline
\end{tabular}




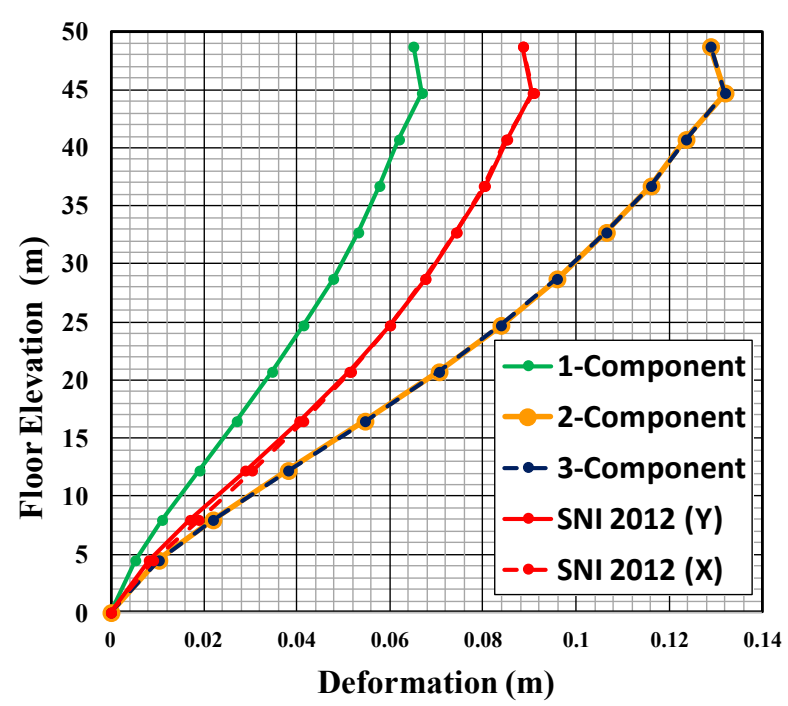

Fig. 15. Comparison of floor deformation due to one, two and three-component SATH caused by Iwate earthquake and SRSA (Y and $\mathrm{X})$.

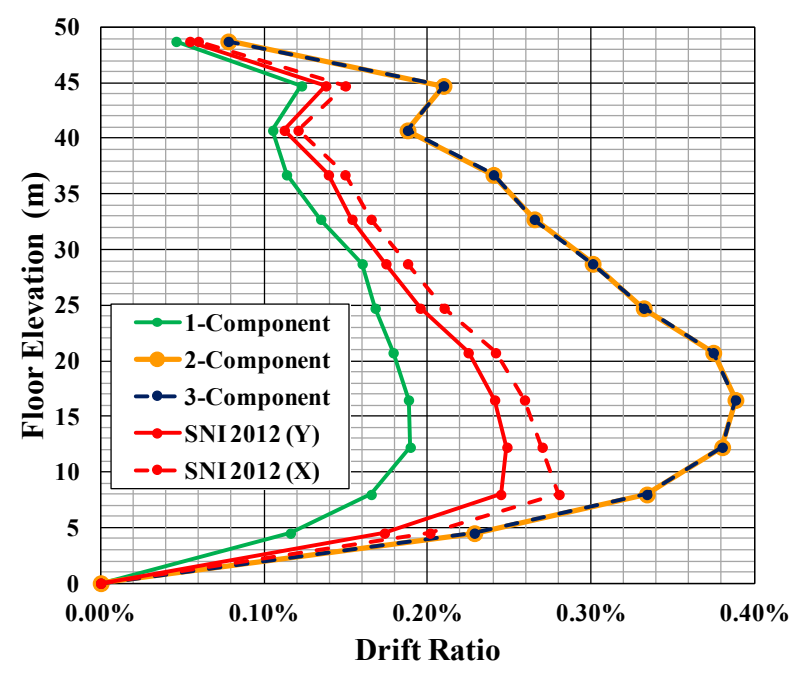

Fig. 16. Comparison of drift ratio due to one, two and threecomponent RATH caused by Iwate earthquake and SRSA (Y and $\mathrm{X}$ ).

\section{Conclusions}

Study for evaluating the stability performance of a building structure, hospital building, in Semarang was carried out by conducting two different earthquake function models, surface response spectral acceleration and surface acceleration time histories. The purpose of the analysis is to obtain the stability performance of the building due to earthquake wave scenarios. The analysis was performed by conducting earthquake forces causes by Semarang fault earthquake scenarios having a maximum magnitude $\mathrm{M}=6.9 \mathrm{Mw}$ and maximum epicentre distance $\mathrm{R}=15 \mathrm{Km}$. The parameters used for building evaluation in this study are the floor deformation and the drift ratio of the building. If the floor deformation and the drift ratio calculated using SRSA model greater than the same values caused by
SATH model, it can be predicted that the building is strong enough to resists the seismic forces caused by Semarang fault earthquake.

Based on the stability evaluation of the building caused by the SRSA, developed from SNI:1726-2012 and the three-component SATH caused by Chi-Chi Taiwan 1999 (6.3 Mw), San Simeon USA 2008 (6.52 $\mathrm{Mw})$ and Iwate Japan 2008 (6.9 Mw), the structure is predicted has a capability on resisting earthquake with magnitude (M) up to $6.5 \mathrm{Mw}$ and epicentre distance (R) greater than $5 \mathrm{Km}$. However if there is an earthquake with $\mathrm{M}=6.9 \mathrm{Mw}$ the building is predicted strong enough on resisting seismic forces if $\mathrm{R}$ is greater than $10 \mathrm{Km}$.

Applying vertical component acceleration time histories for structure model depends on the joint reaction model used in the structural analysis. The joint reaction model of the structure depends on the foundation used in the building. Fix end joint reaction model used in the building structure model has no impact on the stability performance of structure due to vertical component acceleration time histories. For safety reason at least two horizontal components ATH (N/S and E/W) needs for stability analysis. Increasing floor deformation by minimum $113.46 \%$ up to $145.52 \%$ compared to common surface response spectral acceleration model shall be paid in attention on the building analysis.

Acknowledgements: This research was financially supported by The Faculty of Engineering, Diponegoro University, Indonesia through Strategic Research Grant 2018.

\section{References}

1. Standard Nasional Indonesia, Tata Cara Perencanaan Struktur Bangunan Gedung dan Non Gedung (Indonesian National Standard, Seismic Code for Building and Other Structures Design), SNI:1726-2012, p.138 (2012)

2. Standard Nasional Indonesia, Persyaratan beton struktural untuk bangunan gedung (Indonesian National Standard, Reinforced Concrete Code for Building Structures), SNI:2847-2013, p.265 (2013)

3. Standard Nasional Indonesia, Beban minimum untuk perancangan bangunan gedung dan struktur lain (Indonesian National Standard, Minimum Loads for Building and Other Structures Design), SNI:17272013, p.198 (2013)

4. D.M. Boore and G.M. Atkinson, Earthq. Spec., Vol. 24, No. 1, pp. 99-138, Earthq. Eng. Res. Inst. (2008)

5. K.W. Campbell and Y. Bozorgnia, Earthq. Spec., Vol. 24, No. 1, pp. 139-171, Earthq. Eng. Res. Inst. (2008)

6. B.S.J. Chiou and R.R. Youngs, NGA Model for Average Horizontal Component of Peak Ground Motion and Response Spectra, (PEER 2008/09, Pacific Engineering Research Centre, College of Engineering, University of California, Berkeley, 2008) 
7. K.W. Campbell and Y. Bozorgnia, Bull. Seism. Soc. of America, 93, no. 1, p. 314-331 (2003)

8. N.A. Abrahamson and W. J. Silva, Seis. Resch. Let., 68, no. 1, p. 94-127 (1997)

9. P. Somerville, N. Collins, N. Abrahamson, R. Graves and C. Saika, Ground Motion Attenuation Relations for the Central and Eastern United States, USGS Reports under award number 99HQGR0098, June 30 (2001)

10. W.D. Iwan, J. of App. Mech., ASME, 34, New York, p. 612-617 (1967)

11. Z. Mroz, J. of Mech. and Phy. of Solids, 15, Elsevier, Rhode Island USA, pp. 163-175 (1967)

12. J.P. Bardet and T. Tobita, NERA A Computer Program for Nonlinear Earthquake Site Response Analysis of Layered Soil Deposits, Dep. of Cv. Eng. Univ. of South. California, p. 44 (2001)

13. Y. Ohsaki and R. Iwasaki, On Dynamics Shear Moduli and Poisson's Ratio of Soil Deposits, (Soil and Foundations, JSSMFE. 13, p. 59-73 (1973)

14. Y. Ohta and N. Goto, Earthq. Eng. and Struc. Dyn., 6, p. 167-187 (1978)

15. T. Imai and K. Tonouchi, Proc. of Sec. Eurp. Symp. on Penetr. Testing, Amsterdam, The Netherlands, p.67-72 (1982)

16. W. Partono, S.P.R. Wardani, M. Irsyam and S. Maarif, J. Teknologi, 78: 8-5, p. 31-38 (2016)

17. Y. Nakamura, The H/V Spectrum, The $14^{\text {th }}$ World Conf. on Earthq. Eng., October 12-17, Beijing, China (2008)

18. Abrahamson N.A., Non Stationary Spectral Matching Program RSPMATCH $>$ PG\&E, Internal Report (1998) 